\title{
Genome sequence and description of the heavy metal tolerant bacterium Lysinibacillus sphaericus strain OT4b.31
}

\author{
Tito David Peña-Montenegro, and Jenny Dussán* \\ Centro de Investigaciones Microbiológicas - CIMIC, Universidad de los Andes, Bogotá, \\ Colombia \\ *Correspondence: jdussan@uniandes.edu.co
}

Keywords: Lysinibacillus sphaericus OT4b.31, DNA homology, de novo assembly, heavy metal tolerance, Sip1A coleopteran toxin

\begin{abstract}
Lysinibacillus sphaericus strain OT4b.31 is a native Colombian strain having no larvicidal activity against Culex quinquefasciatus and is widely applied in the bioremediation of heavy-metal polluted environments. Strain OT4b.31 was placed between DNA homology groups III and IV. By gap-filling and alignment steps, we propose a 4,096,672 bp chromosomal scaffold. The whole genome (consisting of 4,856,302 bp long, 94 contigs and 4,846 predicted proteincoding sequences) revealed differences in comparison to the L. sphaericus C3-41 genome, such as syntenial relationships, prophages and putative mosquitocidal toxins. Sphaericolysin B354, the coleopteran toxin Sip1 A and heavy metal resistance clusters from nik, ars, czc, cop, chr, czr and cad operons were identified. Lysinibacillus sphaericus OT4b.31 has applications not only in bioremediation efforts, but also in the biological control of agricultural pests.
\end{abstract}

\section{Introduction}

Biological control of vector-borne diseases, such as dengue and malaria, and agricultural pests have been an issue of special concern in the recent years. Since Kellen et al. [1] first described Lysinibacillus sphaericus as an insect pathogen, studies have shown mosquitoes to be the major target of this bacterium [2-4], but toxic activity against other species has also been reported [5,6]. L. sphaericus larvicidal toxicity has been reported due to vegetative mosquitocidal toxins (Mtx) [7], the binary toxin (BinA/BinB) [4], Cry48/Cry49 toxin [8] and recently the S-layer protein [9]. To date, no larvicidal activity has been identified in Lysinibacillus sphaericus 0T4b.31 against Culex quinquefasciatus [10].

On the other hand, Lysinibacillus species are potential candidates for heavy metal bioremediation. Some Bacillaceae strains have been successfully isolated from nickel contaminated soil [11], industrial landfills [12], naturally metalliferous soils [13] and a uranium-mining waste pile [14]. In addition, native Colombian Lysinibacillus strains have been reported as potential metal bioremediators. Strain CBAM5 is resistant to arsenic, up to $200 \mathrm{mM}$, and contains the arsenate reductase gene [15]. L. sphaericus OT4b.31 showed heavy metal biosorption in living and dead biomass. The S-layer protein was also shown to be present [16]. We observed 19 mosquitopathogenic L. sphaericus strains and 6 nonpathogenic strains (including 0T4b.31) that were able to grow in arsenate, hexavalent chromium and/or lead [17]. The moderate heavy metal tolerance in a Lysinibacillus strain isolated from a non-polluted environment generates interest in characterizing the genomic properties of $L$. sphaericus 0T4b.31, in addition to its biotechnological potential in biological control.

Here we present a summary classification and a set of features for Lysinibacillus sphaericus 0T4b.31 including previously unreported aspects of its phenotype, together with the description of the complete genomic sequencing and annotation. 


\section{Classification and features}

Formerly known as Bacillus sphaericus, the species was defined as having a spherical terminal spore and by its inability to ferment sugars [18]. According to physiological and phylogenetic analysis, it was reassigned to the genus Lysinibacillus [19]. Strains of L. sphaericus can be divided into five DNA homology groups (I-V). Some mosquito pathogenic strains are allocated in subgroup II-A, while Lysinibacillus fusiformis species is in subgroup II-B [20]. Later, according to $16 \mathrm{~S}$ rDNA and lipid profile comparisons, Lysinibacillus sphaericus sensu lato was classified into seven similarity subgroups, of which only four retained the previous description by Krych et al. [21]. Recently, by using $16 \mathrm{~S}$ rDNA phylogenetic analysis some mosquito pathogenic native strains were found in group II with heterogeneous heavy metal tolerance levels. [17].

Partial 16S rRNA gene sequences $(1,421 \mathrm{bp})$ were aligned to establish the phylogenetic neighborhood of Lysinibacillus sphaericus OT4b.31 (Figure 1). The phylogenetic tree was constructed by neighbor-joining [23] using the SEAVIEW [24] and TreeGraph2 [25] packages. Genetic distances were estimated by using the Jukes-Cantor model [23]. The stability of relationships was assessed by bootstrap analysis based on 1,000 resamplings for the tree topology. Interestingly, L. sphaericus 0T4b.31 did not fall into any existing DNA similarity group; it was found between DNA similarity groups III and IV [21]. Consistent with Lozano \& Dussán [17], L. sphaericus OT4b.31 did not fall into DNA similarity groups I, II or III.

Dussán et al. [10] evaluated physiological diversity and genetic potential in native Bacillaceae isolates from highlands of the Colombian Andes, where Lysinibacillus sphaericus 0T4b.31 was first described (Table 1). L. sphaericus 0T4b.31 is an aerobic free-living bacterium isolated from coleopteran (beetle) larvae collected in the highlands of the Colombian Andes [10]. Vegetative cells stain Gram positive, but in sporulating stages, cell stain Gram variable (Figure 2). By using a JEOL JSM-5800LV (Japan) scanning electron microscope, L. sphaericus 0T4b.31 is estimated to measure 0.61 to $0.65 \mu \mathrm{m}$ in width and 1.9 to 2.3 $\mu \mathrm{m}$ long (Figure 3). L. sphaericus HOT4b.31 showed slow sporulation rates (undetectable up to 40 hours of growth) and positive evidence of binary toxin which does not exhibit larvicidal activity against Culex quinquefasciatus [10]. Cultures grow at 10 to $40^{\circ} \mathrm{C}$ over a pH range of 6.0 to 9.0. Antibiotic resistance was evaluated separately by adding filter sterilized antibiotic solutions in Luria-Bertani broths and checking turbidity after 15 hours of growth. L. sphaericus 0T4b.31 is sensitive to kanamycin $(12.5 \mu \mathrm{g} / \mathrm{mL})$, chloramphenicol $(25 \mu \mathrm{g} / \mathrm{mL})$, erythromycin $(5 \mu \mathrm{g} / \mathrm{mL})$, and gentamicin $(25 \mu \mathrm{g} / \mathrm{mL})$, while it showed resistance to trimethoprim/sulfamethoxazol up to $30 \mu \mathrm{g} / \mathrm{mL} / 150 \mu \mathrm{g} / \mathrm{mL}$.

\section{Genome sequencing information Genome project history}

The genome sequencing of Lysinibacillus sphaericus 0T4b.31 was supported by the CIMIC (Centro de Investigaciones Microbiológicas) laboratory at the University of Los Andes within the Grant (1204-452-21129) of the Instituto Colombiano para el fomento de la Investigación Francisco José de Caldas. Whole genomic DNA extraction and bioinformatics analysis was performed at CIMIC laboratory, whereas libraries construction and whole shotgun sequencing at the Beijing Genome Institute (BGI) Americas Laboratory (Tai Po, Hong Kong). The applied pipeline included quality check of reads, de novo assembly, a gap-filling step and mapping against a reference genome. This whole genome shotgun project has been deposited at DDBJ/EMBL/GenBank under the accession AQPX00000000. The version described in this paper is the first version, AQPX01000000. A summary of the project information is shown in Table 2.

\section{Growth conditions and DNA isolation}

Lysinibacillus sphaericus strain 0T4b.31 was grown in nutrient broth for 16 hours at $30^{\circ} \mathrm{C}$ and $150 \mathrm{rev} / \mathrm{min}$. High molecular weight DNA was isolated using the EasyDNA ${ }^{\circledR}$ Kit (Carlsbad, CA, USA. Invitrogen) as indicated by the manufacturer. DNA purity and concentration were determined in a NanoDrop spectrophotometer (Wilmington, DE, HUSA. Thermo Scientific). 
Table 1. Classification and general features of Lysinibacillus sphaericus OT4b.31 according to the MIGS recommendations [26]

\begin{tabular}{|c|c|c|c|}
\hline MIGS ID & Property & Term & Evidence code $^{a}$ \\
\hline & & Domain Bacteria & TAS [27] \\
\hline & & Phylum Firmicutes & TAS [28-30] \\
\hline & & Class Bacilli & TAS $[31,32]$ \\
\hline & Current classification & Order Bacillales & TAS $[33,34]$ \\
\hline & & Family Bacillaceae & TAS $[33,35]$ \\
\hline & & Genus Lysinibacillus & TAS $[19,36]$ \\
\hline & & Species Lysinibacillus sphaericus & TAS $[19,37]$ \\
\hline & & Type strain OT4b.31 & TAS [10] \\
\hline & Gram stain & Positive in vegetative cells, variable in sporulating stages & IDA \\
\hline & Cell shape & Straight rods & IDA \\
\hline & Motility & Non-motile & IDA \\
\hline & Sporulation & Sporulating & IDA \\
\hline & Temperature range & Mesophile, grows $>14^{\circ},<37^{\circ} \mathrm{C}$ & TAS [10] \\
\hline & Optimum temperature & $30^{\circ} \mathrm{C}$ & TAS [10] \\
\hline & Carbon source & Complex carbohydrates & TAS [10] \\
\hline & Energy metabolism & Heterotroph & TAS [10] \\
\hline MIGS-6 & Habitat & Coleopteran (beetle) larvae & TAS [10] \\
\hline MIGS-6.3 & Salinity & Growth in Luria-Bertani broth $(5 \% \mathrm{NaCl})$ & IDA \\
\hline MIGS-22 & Oxygen requirement & Aerobic & TAS [10] \\
\hline MIGS-15 & Biotic relationship & Free living & TAS [10] \\
\hline MIGS-14 & Pathogenicity & Unknown & TAS [10] \\
\hline MIGS-4 & Geographic location & Tenjo, Cundinamarca, Colombia & TAS [10] \\
\hline MIGS-5 & Sample collection time & 1995 & TAS [10] \\
\hline MIGS-4.1 & Latitude & 4.88727 & TAS [10] \\
\hline MIGS-4.2 & Longitude & -74.132831 & TAS [10] \\
\hline MIGS-4.3 & Depth & Surface & TAS [10] \\
\hline MIGS-4.4 & Altitude & 2,685 $\mathrm{m}$ above sea level & TAS [10] \\
\hline
\end{tabular}

a) Evidence codes - IDA: Inferred from Direct Assay; TAS: Traceable Author Statement (i.e., a direct report exists in the literature); NAS: Non-traceable Author Statement (i.e., not directly observed for the living, isolated sample, but based on a generally accepted property for the species, or anecdotal evidence). These evidence codes are from the Gene Ontology project [38]. 


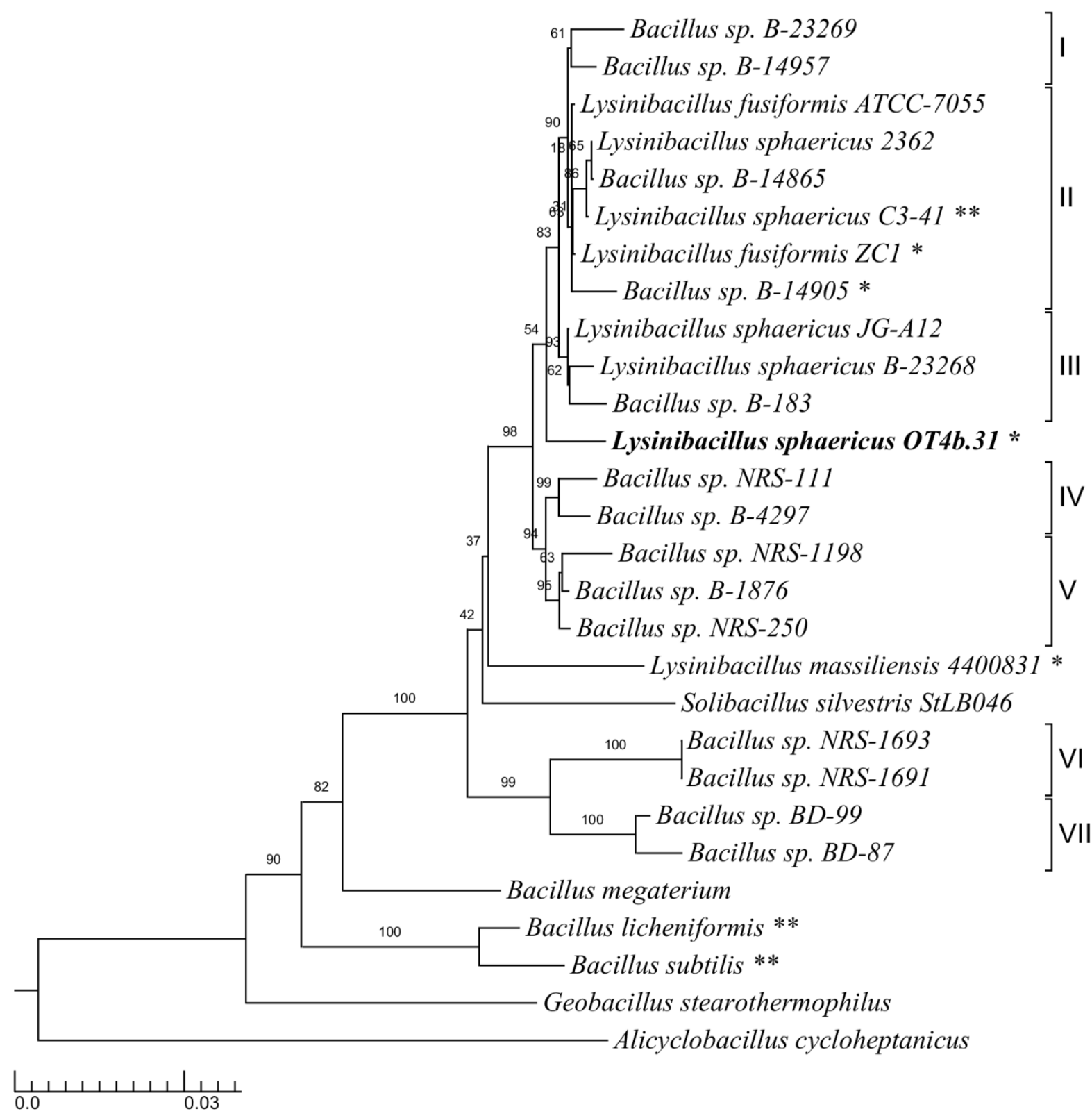

Figure 1. Phylogenetic tree highlighting the position of Lysinibacillus sphaericus OT4b.31 relative to the available type strains and other non-assigned species within the families Alicyclobacillaceae and Bacillaceae. Alicyclobacillus cycloheptanicus was designated as the outgroup species for the analyses. Right brackets encompass each homology group (I-VII) according to Nakamura's benchmarks [21]. Nucleotide sequences obtained from GenBank and used in the phylogenetic analyses were as follows: Alicyclobacillus cycloheptanicus 1457 (X51928), Geobacillus stearothermophilus 10 (X57309), Bacillus subtilis 168 (X60646), Bacillus licheniformis DSM 13 (X68416), Bacillus megaterium IAM 13418 (D16273), Bacillus sp. BD-87 (AF169520), Bacillus sp. BD-99 (AF169525), Bacillus sp. NRS-1691 (AF169531), Bacillus sp. NRS-1693 (AF169533), Solibacillus silvestris StLB046 (NR_074954), Lysinibacillus massiliensis 4400831 (NR_043092), Bacillus sp. NRS-250 (AF169536), Bacillus sp. B-1876 (AF169494), Bacillus sp. NRS-1198 (AF169528), Bacillus sp. B-4297 (AF169507), Bacillus sp. NRS-111 (AF169526), Lysinibacillus sphaericus OT4b.31 (AQPX00000042.1:91-1546), Bacillus sp. B-183 (AF169493), Lysinibacillus sphaericus B-23268 (AF169495), Lysinibacillus sphaericus JG-A12 (AM292655), Bacillus sp. B-14905 (AF169491), Lysinibacillus sphaericus ZC1 (NZ_ADJR01000054.1:1-1487), Lysinibacillus sphaericus C3-41 (NC_010382.1:16887-18287), Bacillus sp. B-14865 (AF169490), Lysinibacillus sphaericus 2362 (L14011), Lysinibacillus fusiformis ATCC-7055 (AJ310083), Bacillus sp. B-14957 (AF169492) and Bacillus sp. B-23269 (AF169496). The branches are scaled in terms of the expected number of substitutions per site. Numbers adjacent to the branches represent percentage bootstrap values based on 1,000 replicates. Lineages with type strain genome sequencing projects registered in GOLD [22] are labeled with one asterisk, those also listed as 'Complete and Published' with two asterisks. 


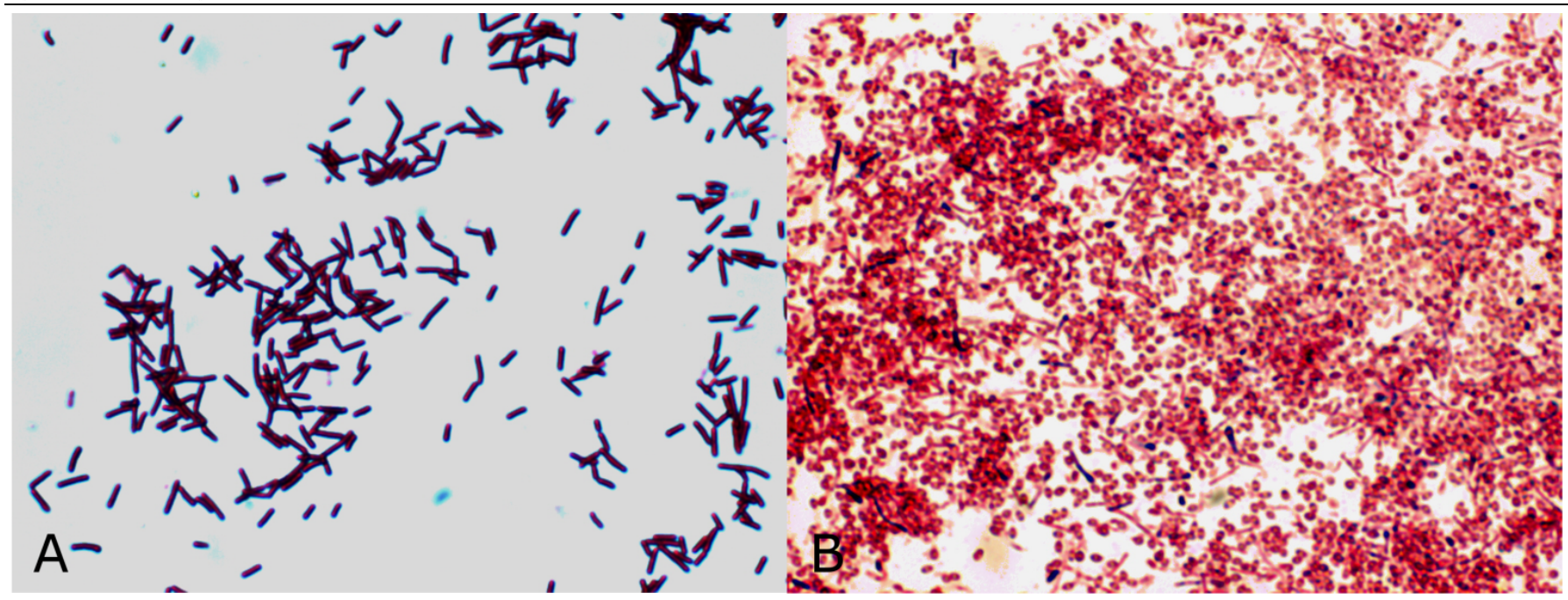

Figure 2. Gram staining of (A) vegetative cells and (B) spores of Lysinibacillus sphaericus OT4b.31.

\section{Genome sequencing and assembly}

After DNA extraction, samples were sent to the Beijing Genome Institute (BGI) Americas Laboratory (Tai Po, Hong Kong). Purified DNA sample was first sheared into smaller fragments with a desired size by a Covaris E210 ultrasonicator. Then the overhangs resulting from fragmentation were converted into blunt ends by using T4 DNA polymerase, Klenow Fragment and T4 polynucleotide kinase. After adding an " $\mathrm{A}$ " base to the 3 ' end of the blunt phosphorylated DNA fragments, adapters were ligated to the ends of the DNA fragments. The desired fragments were purified though gelelectrophoresis, then selectively enriched and amplified by PCR. The index tag was introduced into the adapter at the PCR stage as appropriate, and a library quality test was performed. Lastly, qualified, short, paired-ends of 90:90 bp length with $500 \mathrm{bp}$ insert libraries were used to cluster preparation and to conduct whole-shotgun sequencing in Illumina Hi-Seq 2000 sequencers.

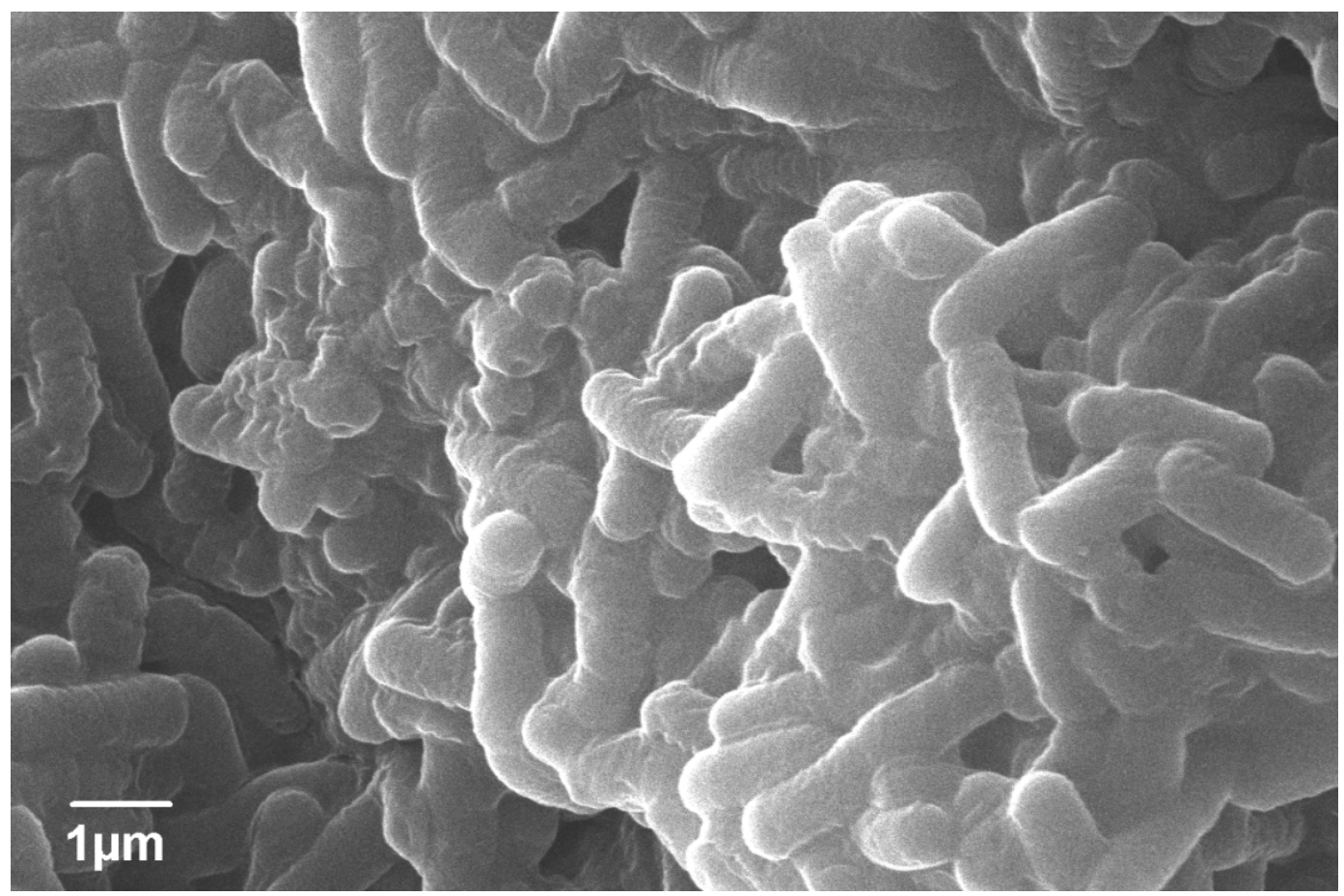

Figure 3. Scanning electron micrograph of Lysinibacillus sphaericus OT4b.31 at an operating voltage of $20 \mathrm{kV}$. 
Peña-Montenegro et al.

Using the FASTX-Toolkit version 0.6.1 [39] and clean_reads version 0.2 .3 from the ngs_backbone pipeline [40] reads were trimmed and quality filtered. Then, with the CLC Assembly Cell version 4.0.10 [41], assembly and scaffolding steps were conducted via a de novo assembly pipeline. The assembly included automatic scaffolding and kmer/overlapping optimization steps. Some gaps were successfully filled by using GapFiller [42] within 30 iterations. No more gaps reached convergence by running more iterations. To obtain structural insight of a chromosomal scaffold, we used CONTIGuator.2 [43], using the Lysinibacillus sphaericus strain C3-41 chromosome (accession number: CP000817.1) as reference. Gap-filling steps and mapping to reference sequences were performed again to confirm convergence. Quality assessment of the assembly was performed with iCORN [44]. The error rate of the final assembly is less than 1 in 1,000,000. Lastly, by using PROmer from the MUMmer [45] and Mauve [46] packages, we compared the chromosomal assembly and the chromosome of L. sphaericus C3-41.

\section{Genome annotation}

The Glimmer 3 gene finder was used to identify and extract sequences for potential coding regions. To achieve the functional annotation steps, the RAST server [47] and Blast2GO pipelines [48] were used. Blast2GO performed the blasting, GOmapping and annotation steps; which included a description according to the ProDom, FingerPRINTScan, PIR-PSD, Pfam, TIRGfam, PROSITE, ProDom, SMART, SuperFamily, Pattern, Gene3D, PANTHER, SignalIP and TM-HMM databases. The results were summarized with InterPro [49]. Additionally, a GO-EnzymeCode mapping step was used to retrieve KEGG pathway-maps. tRNA genes were identified by using tRNAscan-SE [50] and rRNA genes by using RNAmmer [51]. The possible orthologs of the genome were identified based on the COG database and classified accordingly [52]. Prophage region prediction was also conducted by using the PHAST tool [53].

\section{Genome properties}

The genome summary and statistics are provided in Tables 3 and 4 and Figure 4 . The genome consists of 96 scaffolds in 4,856,302 bp total size with a GC content of $37.5 \%$. A total of 23 scaffolds were successfully aligned to a reference sequence, comprising 4,096,672 bp of sequence and are represented by the red and blue bars within the outer ring of Figure 4. Of the 4,938 genes predicted, 4,846 were protein-coding genes, 46 RNAs, and 1,623 pseudogenes were identified. Genes assigned a putative function comprised $67.13 \%$ of the protein-coding genes while the remaining ones were annotated as hypothetical proteins. The distribution of genes into COGs functional categories is presented in Table 5.

Table 2. Genome sequencing project information

\begin{tabular}{lll}
\hline MIGS ID & Property & Term \\
\hline MIGS-31 & Finishing quality & Improved high-quality draft \\
MIGS-28 & Libraries used & One paired end tags 90:90 bp with 500 bp insert \\
MIGS-29 & Sequencing platforms & Illumina Hi-Seq 2000 \\
MIGS-31.2 & Fold coverage & 100× \\
MIGS-30 & Assemblers & CLC Assembly Cell version 4.0.10 \\
MIGS-32 & Gene calling method & Glimmer3, tRNAscan-SE \\
& Genbank ID & AQPX00000000 \\
& Genbank Date of Release & May 10, 2013 \\
& GOLD ID & Gi39289 \\
& Project relevance & Biotechnology, metabolic pathway \\
\hline
\end{tabular}




\begin{tabular}{lcll} 
Table 3. Summary of genome & & & \\
\hline Label & Size (Mb) & Topology & INSDC identifier \\
\hline Chromosomal scaffold & $4,096,672$ & Circular & KB933398.1 \\
& & & \\
Extrachromosomal elements & 759,630 & Linear & KB933399.1-KB933469.1 \\
\hline
\end{tabular}

Table 4. Nucleotide content and gene count levels of the genome

\begin{tabular}{|c|c|c|}
\hline Attribute & Value & $\%$ of total \\
\hline Genome size (bp) & $4,856,302$ & 100.00 \\
\hline DNA GC content (bp) & $1,821,262$ & 37.50 \\
\hline DNA coding region (bp) & $3,924,297$ & 80.81 \\
\hline Number of replicons & 1 & \\
\hline Extrachromosomal & 0 & \\
\hline Total genes & 4,938 & 100 \\
\hline RNA genes & 46 & 0.93 \\
\hline rRNA operons & 7 & \\
\hline tRNA genes & 38 & 0.77 \\
\hline Pseudogenes & 1,623 & 32.87 \\
\hline Protein-coding genes & 4,846 & 98.14 \\
\hline Genes in paralog clusters & 658 & 13.33 \\
\hline Genes assigned to COGs & 2,946 & 59.66 \\
\hline 1 or more conserved domains & 2,946 & 59.66 \\
\hline 2 or more conserved domains & 529 & 10.71 \\
\hline 3 or more conserved domains & 98 & 1.98 \\
\hline Genes with function prediction & 3,315 & 67.13 \\
\hline Genes assigned Pfam domains & 2,799 & 56.68 \\
\hline Genes with signal peptides & 1,206 & 24.42 \\
\hline Genes with transmembrane helices & 1,206 & 24.42 \\
\hline CRISPR repeats & 0 & 0.00 \\
\hline
\end{tabular}

a) The total is based on either the size of the genome in base pairs or the total number of protein coding genes in the annotated genome. 
Table 5. Number of genes associated with the 25 general COG functional categories

\begin{tabular}{crrl}
\hline Code & Value & \%age $^{\mathbf{a}}$ & Description \\
\hline J & 180 & 3.80 & Translation \\
A & 118 & 2.49 & RNA processing and modification \\
K & 354 & 7.48 & Transcription \\
L & 167 & 3.53 & Replication, recombination and repair \\
B & 1 & 0.02 & Chromatin structure and dynamics \\
D & 37 & 0.78 & Cell cycle control, mitosis and meiosis \\
Y & 0 & 0 & Nuclear structure \\
V & 75 & 1.58 & Defense mechanisms \\
T & 293 & 6.19 & Signal transduction mechanisms \\
M & 159 & 3.36 & Cell wall/membrane biogenesis \\
N & 95 & 2.01 & Cell motility \\
Z & 31 & 0.66 & Cytoskeleton \\
W & 28 & 0.59 & Extracellular structures \\
U & 48 & 1.01 & Intracellular trafficking and secretion \\
O & 96 & 2.03 & Posttranslational modification, protein turnover, chaperones \\
C & 169 & 3.57 & Energy production and conversion \\
G & 146 & 3.09 & Carbohydrate transport and metabolism \\
E & 351 & 7.42 & Amino acid transport and metabolism \\
F & 85 & 1.80 & Nucleotide transport and metabolism \\
H & 142 & 3.00 & Coenzyme transport and metabolism \\
I & 133 & 2.81 & Lipid transport and metabolism \\
P & 273 & 5.77 & Inorganic ion transport and metabolism \\
Q & 98 & 2.07 & Secondary metabolites biosynthesis, transport and catabolism \\
R & 450 & 9.51 & General function prediction only \\
S & 234 & 4.95 & Function unknown \\
- & 1,694 & 37.74 & Not in COGs \\
\hline
\end{tabular}

a) The total is based on the total number of protein coding genes in the annotated genome.

\section{Insights into the genome}

To complete the assembly process, a resequencing pipeline was applied that set whole genome sequences as references such as Lysinibacillus sphaericus C3-41, Bacillus sp. strain B-14905, Bacillus sp. NRRL B-14911, Bacillus megaterium QM B1551, Bacillus anthracis Ames, Lysinibacillus boronitolerans F1182 and Lysinibacillus fusiformis ZC1. Mapping coverage was lower than $30 \%$ in any case (data not shown). In addition, GC content, and depth-GC correlation analysis demonstrated neither a biased distribution nor heterogeneity in the GC content of raw data. Thus, a de novo assembly was conducted in the CLC Assembly Cell version 4.0.10, as discussed above, resulting in a 123scaffold assembly with a N50=96,816 bp. After the gap-filling step, all intrascaffold gaps and 29 interscaffold gaps were closed, leaving 94 scaffolds with a N50=205,086 bp. Finally, a mapping step was conducted using the sequences mentioned above as references. This yielded 26 supercontigs that mapped to L. sphaericus strain C3-41 chromosome corresponding to $88.9 \%$ of the reference chromosome. This alignment was proposed as a chromosomal scaffold. Other reference sequences lead to no significant coverage levels and extrachromosomal scaffolds did not align to previously sequenced plasmids of related species (data not shown). Chromosomal comparison from the PROmer analysis between $L$. sphaericus strains OT4b.31 and C3-41 showed that most of the two chromosomes mapped onto each other, revealing large segments of high similarity (Figure 5). However, a region comprising around 2 to $3.25 \mathrm{Mbp}$ in the C3-41 chromosome and the contigs 15 to 19 in 
the chromosomal scaffold were remarkably scattered in the dot-plot, revealing low coverage levels and different syntenial relationships to the reference sequence.

The origin of replication of the chromosome of $L$. sphaericus 0T4b.31 was estimated by similarities to several features of the corresponding regions in L. sphaericus C3-41, Bacillus sp. B-14905 and other close related bacteria, including colocalization of the genes: $d n a X, r e c R$, holB, dnaA, recG and recA; and $\mathrm{GC}$ nucleotide skew $[(\mathrm{G}-\mathrm{C}) /(\mathrm{G}+\mathrm{C})]$ analysis. In the first $40 \mathrm{Kbp}$ of contig 1, we found $\operatorname{dnaX}$, recR, and $h o l B$, while $d n a A, \operatorname{rec} G$ and $\operatorname{rec} A$ were found at the end (after $290 \mathrm{Kbp}$ ) of contig 13 . This may suggest that contig 13 should be allocated immediately before contig 1 . Besides, there was no evidence of multiple dnaA boxes around the potential origin.
The replication termination site of the chromosomal scaffold is believed to be localized near 2.5 Mbp in the contig 18, according to GC skew analysis, and the coding bias for the two strands of the chromosome is for the majority of CDSs to be on the outer strand from 0 to $\sim 2.5 \mathrm{Mbp}$ and on the inner strand from $\sim 2.5 \mathrm{Mbp}$ to the end of the chromosomal scaffold (contig 26, Figure 4). This was also confirmed by the presence of parC (H131_12178) and parE (H131_12183), which encode the subunits of the chromosome-partitioning enzyme topoisomerase IV [54]. Similar to the $L$. sphaericus C3-41 genome [55], we did not find the homolog of rtp (replication terminator proteinencoding gene) in the chromosomal assembly of OT4b.31.

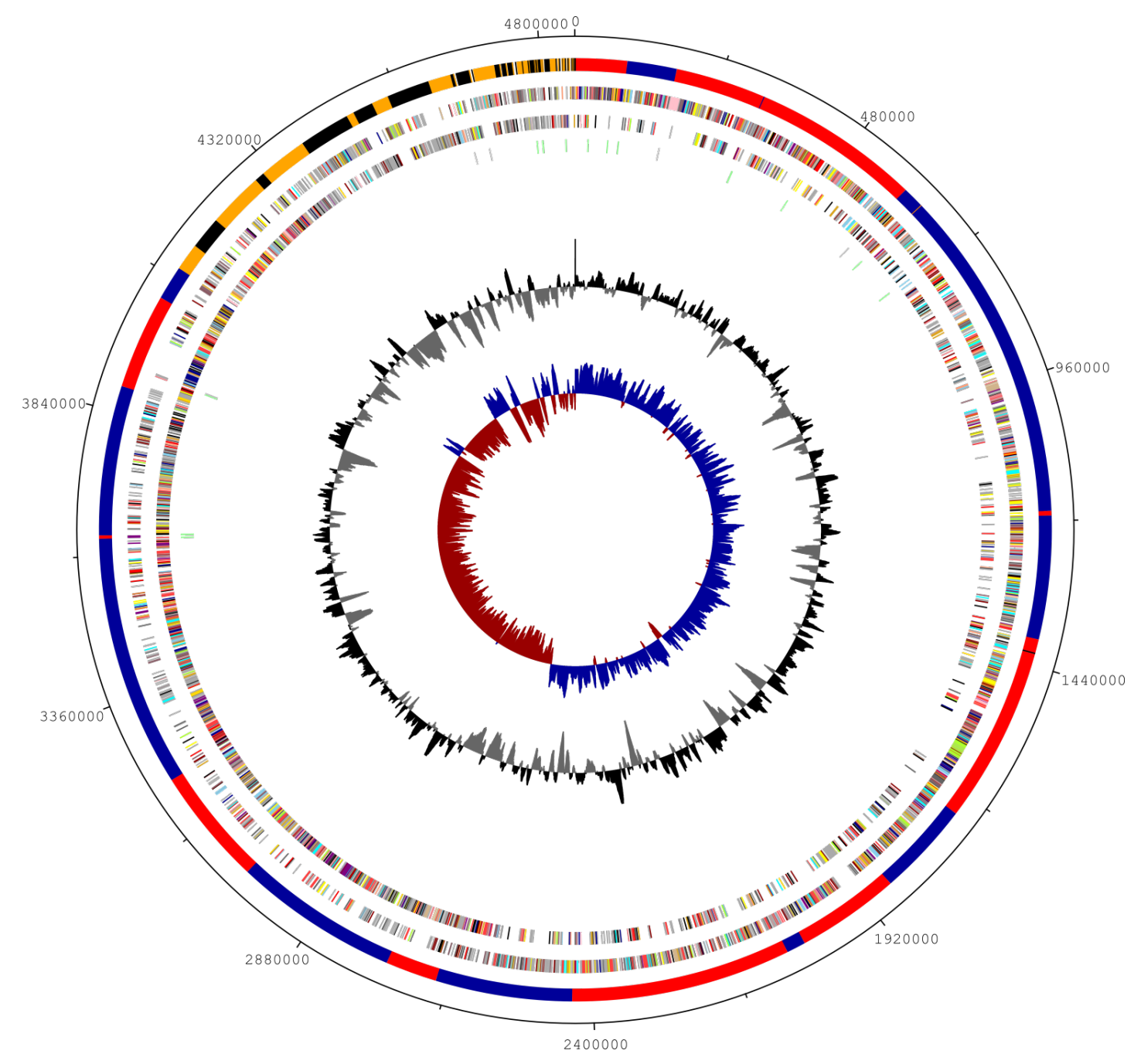

Figure 4. Graphical map of the genome. From outside to the center: Ordered and oriented scaffolds assigned to chromosome in blue and red, extrachromosomal scaffolds in orange and black, Genes on forward strand (color by COG categories), Genes on reverse strand (color by COG categories), RNA genes (tRNAs green, rRNAs gray), GC content and GC skew. 

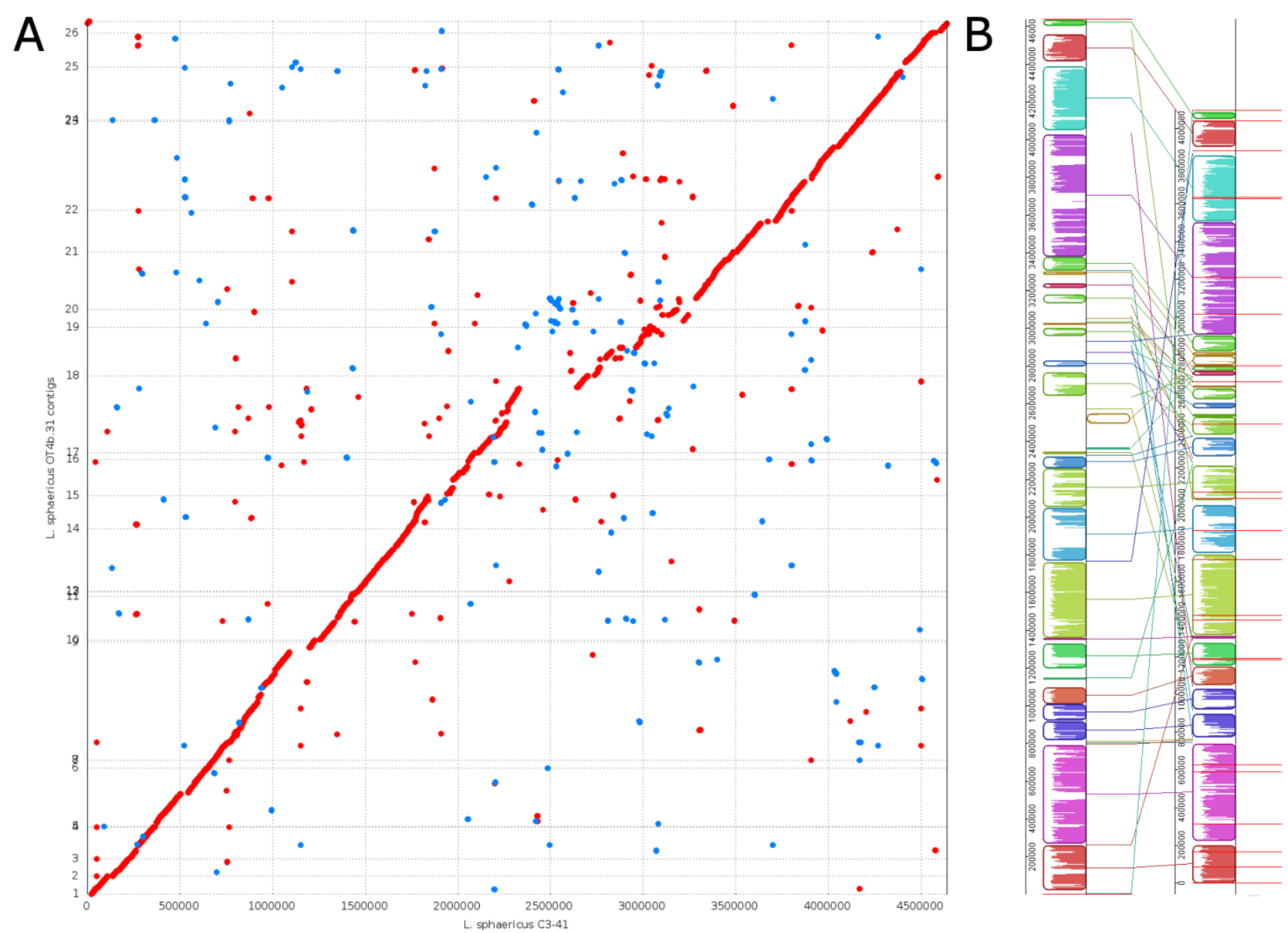

Figure 5. (A) Dot-plot of amino-acid-based alignment of a $4.09 \mathrm{Mbp}$ chromosomal scaffold of L. sphaericus OT4b.31 (y-axis) to a $4.6 \mathrm{Mbp}$ chromosome of L. sphaericus C3-41 (x-axis). Aligned segments are represented as dots or lines. Forward matches are plotted in red, reverse matches in blue. Figure generated by PROmer [45]. (B) Nucleotide-based alignment of a 4.09 Mbp chromosomal scaffold of L. sphaericus OT4b.31 (right) to a 4.6 Mbp chromosome of L. sphaericus C3-41 (left). A total of 27 homologous blocks are shown as identically colored regions and linked across the sequences. Regions that are inverted relative to L. sphaericus OT4b.31 are shifted to the right of center axis of the sequence. The origin of replication in each sequence is approximately at coordinate 1 . Red bars show the limits of each contig in the chromosomal scaffold. Contigs 1 to 26 are numbered in ascending order start in coordinate 1. The figure was generated by Mauve [46].

A total of 42 hypothetical protein coding sequences were assigned as putative transposable elements, with the most frequent families being IS66, IS110, IS1272 and IS3. In addition, five prophage regions were identified, of which one region is intact and 4 regions are incomplete. Lactobacillus phage C5 (intact), Bacillus phage $\varphi 105$, Clostridium phage c-st, Bacillus Phage SPP1 and Bacillus phage $\mathrm{W} \beta$ predicted regions were allocated at contigs $34,8,15,18$ and 37, respectively. Only lysis proteins were predicted in phages $\mathrm{C} 5$ and cst regions. The only genes remaining in the phage $\varphi 105$ region are those for coat proteins, integrase, and hypothetical and phage-like coding sequences. This is probably the remnant of phage invasion and genome deterioration during evolution. In addition, any previously reported phages in the genome of L. sphaericus C3-41 are in the genome of 0T4b.31.

Two elements contain conserved domains from the Listeria pathogenicity island LIPI-1, functionally assigned as a thiol-activated cytolysin and a phosphatidylinositol phospholipase C. The first was confirmed to correspond to the L. sphaericus B354 sphaericolysin coding gene in contig 18 
(H131_12483). Sphaericolysin B354 has been reported to be widespread across L. sphaericus DNA homology groups not only including IIA, IIB, IV and $V$ [56] but also non-grouped species such as OT4b.31. Upstream, in the same contig, a Bacillus toxin from the family Mtx2 (PFam PF03318) was found and described as a hypothetical Sip1A toxin coding sequence (H131_12498). Purified from $\mathrm{Ba}$ cillus thuringiensis strain EG2158, Sip1A is a secreted insecticidal protein of $38 \mathrm{KDa}$ having activity against Colorado Potato beetle (Leptinotarsa decemlineata) [57]. Considering that L. sphaericus OT4b.31 was isolated from beetle larvae, we suggest potential coleopteran larvicidal activity. To our knowledge, strain 0T4b.31 is the first report of a predicted Sip1A-like toxin in a native Lysinibacillus sphaericus. Unexpectedly, $m t x$ or bin mosquito pathogenic genes were not found in the OT4b.31 genome, despite a previous report showing positive evidence of BinA/B toxins with no larvicidal activity [10].

A total of 32 CDSs were described as surface (S) layer proteins or S-layer homologs (SLH). The putative S-layer gene sllB (H131_05299) previously reported in L. sphaericus JG-A12 [58] was found in a 3,696 bp sequence allocated in contig 8. Three sequences with conserved domains similar to Slp5 and Slp6 were identified in contigs 8 (H131_05339, H131_05344) and 22 (H131_16838). Bacillus sp. B-14905 was the most similar sequence for the majority of $S$-layer protein domains. In addition, a putative glycoprotein (H131_22117), a bifunctional periplasmic precursor (H131_05993) and an S-layer fusion (H131_05409) coding sequence associated with Slayer proteins were recognized. On the other hand, a cluster of spore germination genes were determined near the termination of the replication site (including genes from the ger and ype operons) among other genes widespread in the genome. Three clusters of sporulation genes were allocated at contigs 1, 10 and 13 (including genes from spoII, spoV, yaa and sig operons).

Responses against toxic metal(oid)s in $L$. sphaericus 0T4b.31 could be controlled by efflux pumps related genes in clusters found in contigs. Putative coding sequence order is as follows: $y o z A \rightarrow c z c D \rightarrow c s o R \rightarrow$ copZA (contig 1, H131_00045: H131_00065); nikABC $\rightarrow$ oppD $\rightarrow$ nikD (contig 17, H131_11103:H131_11123); $\quad$ cadC-like $\rightarrow$ cadA (contig 24, H131_17086:H131_17081); $\operatorname{arsRBC}$ putative extracellular secreted protein CDS - arsR- like $\rightarrow$ ars $R$-like $\rightarrow$ putative excinuclease CDS (contig 18, H131_11998:H131_12028). The function of YozA is still unknown [59], but is similar to CzrA and CadC belonging to the ArsR transcriptional family regulators. YozA, CsoR (from the copper-sensitive operon), CadC-like and ArsR proteins seem to be the direct regulators of each cluster. At least one additional copy of ChrA, CzrB and CzcD CDSs were found. Upstream the nik cluster, we could not find transcriptional regulators. In summary, L. sphaericus 0T4b.31 has protein encoding sequences probably involved in the resistance against $\mathrm{Cd}, \mathrm{Zn}, \mathrm{Co}, \mathrm{Cu}, \mathrm{Ni}, \mathrm{Cr}$, and $\mathrm{As}$. In fact, prior reports of resistance to toxic metals $[16,17]$ in L. sphaericus OT4b.31 may be explained due to participation of heavy-metal resistance proteins.

Strain 0T4b.31 probably has a diverse defense repertoire according to the following responses and predicted genes: bacitracin stress responses, genes bceBASR and yvcPQRS; multidrug resistance, MATE (multidrug and toxin extrusion) family efflux pump genes ydhE/norM and $a c r B$; antibiotics resistance, genes vanRSW, tetP-like group II, fus $A$ (elongation factor $\mathrm{G}$ ), fosB, blaZ and $a m p C$-like. Based in the KEGG analysis, some predicted proteins might participate in peripheral pathways for the degradation of benzoate, aminobenzoate, quinate, toluene, naphthalene, geraniol, limonene, pinene, chloroalkane, chloroalkene, styrene, ethilbenzene, caprolactam and atrazine compounds, and biosynthesis of streptomycin, novobiocin, zeatin, ansamycins, penicillin and cephalosporins.

\section{Conclusions}

The native Colombian strain Lysinibacillus sphaericus 0T4b.31, isolated from beetle larvae, is classified between DNA similarity groups III and IV. A comparison of the chromosomal sequences of strain OT4b.31 and its closest complete genome sequence, L. sphaericus C3-41, demonstrates the presence of only a few similar regions with syntenial rearrangements, and no prophage or putative mosquitocidal toxins are shared. Sphaericolysin B354 and the coleopteran toxin Sip1A were predicted in the strain 0T4b.31, a finding which may be useful not only in bioremediation of polluted environments, but also for biological control of agricultural pests. Finally, $\mathrm{Cd}, \mathrm{Zn}$, $\mathrm{Co}, \mathrm{Cu}, \mathrm{Ni}, \mathrm{Cr}$ and As resistances probably are supported by efflux pumps genes. 


\section{Acknowledgements}

We would like to gratefully acknowledge the help of Dr. rer. nat. Diego Riaño-Pachón at Centro Nacional de Pesquisa em Energia e Materiais for his instructions in data analysis and the Group of Computational and Evolutionary Biology at the University of Los Andes for providing us access to the computing grid cluster. This

\section{References}

1. Kellen WR, Clark TB, Lindegren JE, Ho BC, Rogoff $\mathrm{MH}$, Singer S. Bacillus sphaericus Neide as a pathogen of mosquitoes. J Invertebr Pathol 1965; 7:442-448. PubMed http://dx.doi.org/10.1016/0022-2011(65)90120-5

2. Porter AG, Davidson EW, Liu JW. Mosquitocidal toxins of bacilli and their genetic manipulation for effective biological control of mosquitoes. Microbiol Rev 1993; 57:838-861. PubMed

3. Berry C. The bacterium, Lysinibacillus sphaericus, as an insect pathogen. J Invertebr Pathol 2012; 109:1-10. PubMed http://dx.doi.org/10.1016/j.jip.2011.11.008

4. Baumann P, Clark MA, Baumann L, Broadwell $\mathrm{AH}$. Bacillus sphaericus as a mosquito pathogen: properties of the organism and its toxins. Microbiol Rev 1991; 55:425-436. $\underline{\text { PubMed }}$

5. Bone LW, Tinelli R. Trichostrongylus colubriformis: Larvicidal activity of toxic extracts from Bacillus sphaericus (strain 1593) spores. Exp Parasitol 1987; 64:514-516. PubMed http://dx.doi.org/10.1016/0014-4894(87)90066-X

6. Key PB, Scott GI. Acute toxicity of the mosquito larvicide, Bacillus sphaericus, to the grass shrimp,Palaemonetes pugio, and mummichog, Fundulus heteroclitus. Bull Environ Contam Toxicol 1992; 49:425-430. PubMed http://dx.doi.org/10.1007/BF01239647

7. Thanabalu T, Porter AG. Efficient expression of a 100-kilodalton mosquitocidal toxin in proteasedeficient recombinant Bacillus sphaericus. Appl Environ Microbiol 1995; 61:4031-4036. PubMed

8. Jones GW, Nielsen-Leroux C, Yang Y, Yuan Z, Dumas VF, Monnerat RG, Berry C. A new Cry toxin with a unique two-component dependency from Bacillus sphaericus. FASEB J 2007; 21:41124120. PubMed http://dx.doi.org/10.1096/fj.078913com

9. Lozano LC, Ayala JA, Dussán J. Lysinibacillus sphaericus S-layer protein toxicity against Culex quinquefasciatus. Biotechnol Lett 2011; 33:2037- work was performed under the auspices of the Grant (1204-452-21129) of the Instituto Colombiano para el fomento de la Investigación Francisco José de Caldas, Colciencias and by the Centro de Investigaciones Microbiológicas - CIMIC laboratory.

2041. PubMed http://dx.doi.org/10.1007/s10529011-0666-9

10. Dussán J, Andrade D, Lozano L, Vanegas S. Caracterización fisiológica y genética de cepas nativas de Bacillus sphaericus. Rev Colomb Biotecnologia 2002; 4:89-99.

11. Abou-Shanab RAI, van Berkum P, Angle JS. Heavy metal resistance and genotypic analysis of metal resistance genes in gram-positive and Gram-negative bacteria present in Ni-rich serpentine soil and in the rhizosphere of Alyssum murale. Chemosphere 2007; 68:360-367. PubMed

http://dx.doi.org/10.1016/j.chemosphere.2006.12. $\underline{051}$

12. Desai $\mathrm{C}$, Jain K, Madamwar D. Evaluation of in vitro $\mathrm{Cr}(\mathrm{VI})$ reduction potential in cytosolic extracts of three indigenous Bacillus sp. isolated from $\mathrm{Cr}(\mathrm{VI})$ polluted industrial landfill. Bioresour Technol 2008; 99:6059-6069. PubMed http://dx.doi.org/10.1016/j.biortech.2007.12.046

13. Pal A, Paul AK. Aerobic chromate reduction by chromium-resistant bacteria isolated from serpentine soil. Microbiol Res 2004; 159:347-354. PubMed http://dx.doi.org/10.1016/j.micres.2004.08.001

14. Selenska-Pobell S, Panak P, Miteva V, Boudakov I, Bernhard G, Nitsche H. Selective accumulation of heavy metals by three indigenous Bacillus strains, $B$. cereus, B. megaterium and $B$. sphaericus, from drain waters of a uranium waste pile. FEMS Microbiol Ecol 1999; 29:59-67.

http://dx.doi.org/10.1111/j.15746941.1999.tb00598.x

15. Villegas-Torres MF, Bedoya-Reina OC, Salazar C, Vives-Florez MJ, Dussan J. Horizontal ars C gene transfer among microorganisms isolated from arsenic polluted soil. Int Biodeterior Biodegradation 2011; 65:147-152. http://dx.doi.org/10.1016/j.ibiod.2010.10.007

16. Velásquez L, Dussan J. Biosorption and bioaccumulation of heavy metals on dead and living biomass of Bacillus sphaericus. I Hazard Mater 
2009; 167:713-716. PubMed

http://dx.doi.org/10.1016/j.jhazmat.2009.01.044

17. Lozano LC, Dussán J. Metal tolerance and larvicidal activity of Lysinibacillus sphaericus. World J Microbiol Biotechnol 2013; 29:13831389. PubMed http://dx.doi.org/10.1007/s11274013-1301-9

18. White PJ, Lotay HK. Minimal nutritional requirements of Bacillus sphaericus NCTC9602 and 26 other strains of this species: the majority grow and sporulate with acetate as sole major source of carbon. J Gen Microbiol 1980; 118:13-19.

19. Ahmed I, Yokota A, Yamazoe A, Fujiwara T. Proposal of Lysinibacillus boronitolerans gen. nov. sp. nov., and transfer of Bacillus fusiformis to Lysinibacillus fusiformis comb. nov. and Bacillus sphaericus to Lysinibacillus sphaericus comb. nov. Int J Syst Evol Microbiol 2007; 57:1117-1125. PubMed http://dx.doi.org/10.1099/ijs.0.63867-0

20. Krych VK, Johnson JL, Yousten AA. Deoxyribonucleic acid homologies among strains of Bacillus sphaericus. Int J Syst Bacteriol 1980; 30:476-484. http://dx.doi.org/10.1099/00207713-30-2-476

21. Nakamura LK. Phylogeny of Bacillus sphaericuslike organisms. Int J Syst Evol Microbiol 2000; 50:1715-1722. PubMed

22. Liolios K, Chen IM, Mavromatis K, Tavernarakis $\mathrm{N}$, Hugenholtz P, Markowitz VM, Kyrpides NC. The Genomes On Line Database (GOLD) in 2009: status of genomic and metagenomic projects and their associated metadata. Nucleic Acids Res 2010; 38:D346-D354. PubMed http://dx.doi.org/10.1093/nar/gkp848

23. Baxevanis AD, Ouellette BFF. Bioinformatics: A Practical Guide to the Analysis of Genes and Proteins. John Wiley \& Sons; 2004.

24. Galtier N, Gouy M, Gautier C. SEAVIEW and PHYLO_WIN: two graphic tools for sequence alignment and molecular phylogeny. Comput. Appl. Biosci. Cabios 1996; 12:543-548. PubMed

25. Stöver BC, Müller KF. TreeGraph 2: Combining and visualizing evidence from different phylogenetic analyses. BMC Bioinformatics 2010; 11:7. PubMed http://dx.doi.org/10.1186/1471-2105-11$\underline{7}$

26. Field D, Garrity G, Gray T, Morrison N, Selengut J, Sterk P, Tatusova T, Thomson N, Allen MJ, Angiuoli SV, et al. The minimum information about a genome sequence (MIGS) specification. Nat Biotechnol 2008; 26:541-547. PubMed http://dx.doi.org/10.1038/nbt1360
27. Woese CR, Kandler O, Wheelis ML. Towards a natural system of organisms: proposal for the domains Archaea, Bacteria, and Eucarya. Proc Natl Acad Sci USA 1990; 87:4576-4579. PubMed http://dx.doi.org/10.1073/pnas.87.12.4576

28. Gibbons NE, Murray RGE. Proposals Concerning the Higher Taxa of Bacteria. Int I Syst Bacteriol 1978; 28:1-6.

http://dx.doi.org/10.1099/00207713-28-1-1

29. Garrity GM, Holt J. The Road Map to the Manual. In: Garrity GM, Boone DR, Castenholz RW (eds), Bergey's Manual of Systematic Bacteriology. Vol 1. Second Edition. New York: Springer; 2001:119-169.

30. Murray RGE. The Higher Taxa, or, a Place for Everything...? In: Holt JG (ed), Bergey's Manual of Systematic Bacteriology.Vol 1. First Edition. Baltimore: The Williams and Wilkins Co.; 1984:3134.

31. Ludwig W, Schleifer K, Whitman W. Class I. Bacilli class nov. In: De Vos P, Garrity GM, Jones D, N.R. Krieg W. Ludwig W, Rainey EA, Schleifer KH, Withman WB (eds) Bergey's Manual of Systematic Bacteriology. In: Vol 3 (The Firmicutes). Second Edition. Dordrecht, Heidelberg, London, New York: Springer; 2009:19-20.

32. List of new names and new combinations previously effectively, but not validly, published. Int J Syst Evol Microbiol 2010; 60:1009-1010. PubMed http://dx.doi.org/10.1099/ijs.0.024562-0

33. Skerman VBD, McGowan V, Sneath PHA. Approved Lists of Bacterial Names. Int / Syst Bacteriol 1980; 30:225-420. http://dx.doi.org/10.1099/00207713-30-1-225

34. Prévot A. Hauduroy P, Ehringer G, Guillot G, Magrou J, Prévot AR, Rosset, Urbain A (eds) Dictionnaire des Bactéries Pathogènes. 2nd ed. Paris: Masson; 1953, p. 1-692.

35. Fischer A. Untersuchungen über bakterien. Jahrbücher Für Wiss. Bot. 1895; 27:1-163.

36. Jung MY, Kim JS, Paek WK, Styrak I, Park IS, Sin Y, Paek J, Park KA, Kim H, Kim HL, Chang YH. Description of Lysinibacillus sinduriensis sp. nov., and transfer of Bacillus massiliensis and Bacillus odysseyi to the genus Lysinibacillus as Lysinibacillus massiliensis comb. nov. and Lysinibacillus odysseyi comb. nov. with emended description of the genus Lysinibacillus. Int I Syst Evol Microbiol 2012; 62:2347-2355. PubMed http://dx.doi.org/10.1099/ijs.0.033837-0 
37. Claus D, Berkeley R. Genus Bacillus Cohn 1872, 174AL. In: Sneath PHA, Mair N, Sharpe M, Holt J, eds. Bergey's Manual of Systematic Bacteriology.Vol 2. Baltimore: The Williams and Wilkins Co.; 1986:1105-1139.

38. Ashburner M, Ball CA, Blake JA, Botstein D, Butler H, Cherry JM, Davis AP, Dolinski K, Dwight SS, Eppig JT, et al. Gene Ontology: tool for the unification of biology. Nat Genet 2000; 25:25-29. PubMed http://dx.doi.org/10.1038/75556

39. FASTX-Toolkit. Available at: http://hannonlab.cshl.edu/fastx_toolkit/. Accessed November 20, 2012.

40. Blanca JM, Pascual L, Ziarsolo P, Nuez F, Cañizares J. ngs_backbone: a pipeline for read cleaning, mapping and SNP calling using Next Generation Sequencing. BMC Genomics 2011; 12:285. PubMed http://dx.doi.org/10.1186/14712164-12-285

41. CLC Genomics Workbench - CLC bio. Clc Bio. Available at: http://www.clcbio.com/products/clcgenomics-workbench/. Accessed November 19, 2012.

42. Boetzer M, Pirovano W. Toward almost closed genomes with GapFiller. Genome Biol 2012; 13:R56. PubMed http://dx.doi.org/10.1186/gb2012-13-6-r56

43. Galardini M, Biondi EG, Bazzicalupo $M$, Mengoni A. CONTIGuator: a bacterial genomes finishing tool for structural insights on draft genomes. Source Code Biol Med 2011; 6:11. PubMed http://dx.doi.org/10.1186/1751-0473-6-11

44. Otto TD, Sanders M, Berriman M, Newbold C. Iterative Correction of Reference Nucleotides (iCORN) using second generation sequencing technology. Bioinformatics 2010; 26:1704-1707. PubMed http://dx.doi.org/10.1093/bioinformatics/btq269

45. Delcher AL, Phillippy A, Carlton J, Salzberg SL. Fast algorithms for large-scale genome alignment and comparison. Nucleic Acids Res 2002;

30:2478-2483. PubMed http://dx.doi.org/10.1093/nar/30.11.2478

46. Darling AE, Mau B, Perna NT. progressiveMauve: multiple genome alignment with gene gain, loss and rearrangement. PLOS ONE 2010; 5:e11147. PubMed http://dx.doi.org/10.1371/journal.pone.0011147

47. Aziz RK, Bartels D, Best AA, Dejongh M, Disz T, Edwards RA, Formsma K, Gerdes S, Glass EM, Kubal M, et al. The RAST Server: Rapid Annota- tions using Subsystems Technology. BMC Genomics 2008; 9:75. PubMed http://dx.doi.org/10.1186/1471-2164-9-75

48. Götz S, García-Gómez JM, Terol J, Williams TD, Nagaraj SH, Nueda MJ, Robles M, Talón M, Dopazo J, Conesa A. High-throughput functional annotation and data mining with the Blast2GO suite. Nucleic Acids Res 2008; 36:3420-3435. PubMed http://dx.doi.org/10.1093/nar/gkn176

49. Apweiler R, Attwood TK, Bairoch A, Bateman A, Birney E, Biswas M, Bucher P, Cerutti L, Corpet F, Croning MD, et al. The InterPro database, an integrated documentation resource for protein families, domains and functional sites. Nucleic Acids Res 2001; 29:37-40. PubMed http://dx.doi.org/10.1093/nar/29.1.37

50. Lowe TM, Eddy SR. tRNAscan-SE: a program for improved detection of transfer RNA genes in genomic sequence. Nucleic Acids Res 1997; 25:955-964. PubMed

51. Lagesen K, Hallin P, Rødland EA, Staerfeldt HH, Rognes T, Ussery DW. RNAmmer: consistent and rapid annotation of ribosomal RNA genes. Nucleic Acids Res 2007; 35:3100-3108. PubMed http://dx.doi.org/10.1093/nar/gkm160

52. Tatusov RL, Natale DA, Garkavtsev IV, Tatusova TA, Shankavaram UT, Rao BS, Kiryutin B, Galperin MY, Fedorova ND, Koonin EV. The COG database: new developments in phylogenetic classification of proteins from complete genomes. Nucleic Acids Res 2001; 29:22-28. PubMed http://dx.doi.org/10.1093/nar/29.1.22

53. Zhou Y, Liang Y, Lynch KH, Dennis JJ, Wishart DS. PHAST: A Fast Phage Search Tool. Nucleic Acids Res. 2011. Available at: http://nar.oxfordjournals.org/content/early/2011/0 6/14/nar.gkr485. Accessed April 26, 2013.

54. Adams DE, Shekhtman EM, Zechiedrich EL, Schmid MB, Cozzarelli NR. The role of topoisomerase IV in partitioning bacterial replicons and the structure of catenated intermediates in DNA replication. Cell 1992; 71:277-288. PubMed http://dx.doi.org/10.1016/0092-8674(92)90356-H

55. Hu X, Fan W, Han B, Liu H, Zheng D, Li Q, Dong W, Yan J, Gao M, Berry C, Yuan Z. Complete genome sequence of the mosquitocidal bacterium Bacillus sphaericus C3-41 and comparison with those of closely related Bacillus Species. I Bacteriol 2008; 190:2892-2902. PubMed http://dx.doi.org/10.1128//B.01652-07

56. From C, Granum PE, Hardy SP. Demonstration of a cholesterol-dependent cytolysin in a 
noninsecticidal Bacillus sphaericus strain and evidence for widespread distribution of the toxin within the species. FEMS Microbiol Lett 2008;

286:85-92. PubMed

http://dx.doi.org/10.1111/j.1574-

6968.2008.01256.x

57. Donovan WP, Engleman JT, Donovan JC, Baum JA, Bunkers GJ, Chi DJ, Clinton WP, English L, Heck GR, Ilagan OM, et al. Discovery and characterization of Sip1A: A novel secreted protein from Bacillus thuringiensis with activity against coleopteran larvae. Appl Microbiol Biotechnol 2006; 72:713-719. PubMed http://dx.doi.org/10.1007/s00253-006-0332-7
58. Pollmann K, Raff J, Schnorpfeil M, Radeva G, Selenska-Pobell S. Novel surface layer protein genes in Bacillus sphaericus associated with unusual insertion elements. Microbiology 2005;

151:2961-2973. PubMed

http://dx.doi.org/10.1099/mic.0.28201-0

59. He M, Li X, Liu H, Miller SJ, Wang G, Rensing C. Characterization and genomic analysis of a highly chromate resistant and reducing bacterial strain Lysinibacillus fusiformis ZC1. J Hazard Mater 2011; 185:682-688. PubMed http://dx.doi.org/10.1016/j.jhazmat.2010.09.072 